\title{
Saber vivir bien es un asunto de la Filosofía
}

Filosofía y ciencias de la complejidad Knowing how to live well is a matter of Philosophy Philosophy and Sciences of Complexity

\author{
Carlos Eduardo Maldonado \\ Profesor titular Facultad de Medicina, Universidad El Bosque \\ maldonadocarlos@unbosque.edu.co \\ ORCID: https://orcid.org/0000-0002-9262-8879 \\ Recepción: 14/09/2021 \\ Aceptación: 26/10/2021
}

\section{Resumen}

Este artículo sostiene una tesis, a saber: que saber vivir y vivir bien son un asunto distintivo de la filosofía, mucho más que de la ciencia, en general. Mientras que la ciencia consiste en una invitación a ver el mundo y la realidad tal cual son, la filosofía se caracteriza por un cambio de actitud frente a lo que es y lo que aparece. Por su parte, sin que sea el tema central aquí, el arte se distingue por crear mundos, realidades, experiencias y dimensiones.

Palabras Clave: Ciencias de la complejidad, vida, conocimiento, experiencia, cambio de actitud

\section{Abstract}

This paper claims that living well and knowing how to live are a particular issue of philosophy, distinctively, rather than a concern belonging to science in general. Whereas science consists in an invitation to face the world and reality as such, philosophy is characterized by a change of attitude vis-à-vis what is or appears. Furthermore, the arts are distinguished by creating brand new worlds, realities, experiences and dimensions; this however is not the main concern here.

Key Words: The sciences of complexity, life, knowledge, experience, change of attitude

\section{Introducción}

Las tres grandes áreas del conocimiento -no las únicas- y de la vida son el arte, la ciencia y la filosofía. Originariamente, al arte precedió a las otras dos, y fue la primera forma como observamos, contamos el universo, y unimos experiencias, unos con otros, y con la naturaleza. El arte nos une a la naturaleza, pero también a los animales. Es sabido cómo también entre los animales existe arte, en general: el juego, la mímica, la música, las canciones, los relatos, una forma de arquitectura, en fin, la danza. Desde los peces hasta los artrópodos, desde las ballenas hasta las aves, desde los mamíferos hasta los arácnidos y los cefalópodos. Hasta donde sabemos. En el futuro, verosímilmente, habremos de descubrir que también el arte existe en las plantas. Sin la menor duda, la ya está establecida la existencia del baile o la danza entre las plantas; los árboles, por ejemplo. Al fin y al cabo, recién en el año 2006 se hizo el descubrimiento de la neurofisiología de las plantas. Desde entonces se ha venido ganando un enorme terreno.

Para los seres humanos, después del arte vino la filosofía. Por lo menos en el relato oficial que nos ha llegado a partir de la Grecia antigua y algunos de sus 
antecedentes. Occidente emerge sobre los pilares de la reflexión filosófica, la indagación por las causas, la emergencia del pensamiento abstracto, en fin, el debate argumentativo. Todo en la plaza pública. Sobre esta base, tiene lugar también, entonces el nacimiento de las incipientes formas de ciencia; las matemáticas primero, la física luego, la geometría. Pero, tal y como la conocemos, la ciencia es un invento perfectamente reciente que tiene lugar después del final de la Edad Media, atravesando por el Renacimiento, y en los orígenes de la Modernidad. La ciencia, tal y como la conocemos, es un invento perfectamente reciente, que tiene apenas alrededor de cuatrocientos años.

Ahora bien, las relaciones entre arte, ciencia y filosofía no siempre han sido armónicas. No bien nace la filosofía, Platón expulsa a los poetas de su República, y Aristóteles le hace eco reduciendo a las artes a un nivel bastante inferior en las escalas de conocimiento. El resto es historia. Por su parte, el nacimiento de la ciencia marca tajantemente la división con respecto a la filosofía. Es lo que sucede con Descartes primero, y luego también con Kant y con Comte.

El lastre de formas jerárquicas de conocimiento y con ellas, formas jerárquicas de organización y de estilos de vida marca y atraviesa de un extremo al otro a las relaciones entre arte, filosofía y ciencia.

Epistemológicamente, el arte siempre ha precedido y anticipado a la ciencia y a la filosofía. Es el ámbito de la libertad y de la imaginación par excellence. La ciencia consiste, dicho de manera simple pero directa, en una invitación a ver, a encontrarnos, a enfrentar lo que hay, lo que sucede, lo que acaece, lo que está allí. Es el llamado a la realidad tal cual es, independientemente de nuestros deseos. Este es su mérito.

Por su parte, las artes no se interesan tanto por la realidad sino, consisten en una superación de la misma. El arte crea mundos, crea realidades, hace posibles dimensiones y experiencias de otra forma inimaginadas. El arte enfrenta a la realidad superándola, creándole otra(s) realidad(es) antes perfectamente inconcebibles. Las artes no se interesan por la realidad en cuanto tal. Sino, por decir lo menos, por sus modalidades.

Por su parte, la filosofía se encuentra en algún lugar intermedio entre el arte y la ciencia. Dicho de manera puntual, la filosofía consiste en la invitación a cambiar la actitud ante la realidad. Se trata, primero, del mito de la caverna, en el Libro VII de la República (Politeia) de Platón, y luego de la epojé entre los estoicos. Se trata, asimismo, de la skepsis a partir del escepticismo antiguo, hasta la duda metódica cartesiana, son olvidar jamás la ironía de Sócrates. En fin, cabe mencionar también, por ejemplo, los análisis del lenguaje desde Bacon hasta Wittgenstein, y las críticas a la razón ins- trumental y el esfuerzo de recuperación de las artes y la estética en la Escuela de Frankfurt, en general. Sin olvidar, jamás las tres transformaciones, de camello en león, y del león en niño, en el Zaratustra de Nietzsche. Los ejemplos y casos pueden multiplicarse a granel.

Hoy vivimos una profunda crisis, sistémica y sistemática., como jamás la ha habido en la historia de la humanidad gracias al carácter globalizado e interdependiente de la cultura en general. Pues bien, este texto sostiene que el llamado a llevar una vida buena, a saber vivir, y a vivir una vida plena -suma qamaña, sumak kawsay, y utz k'aslemal, en quechua, aymara y quiché, respectivamente, por ejemplo-, es el oficio exactamente de la filosofía, y se aportarán argumentos de diversa índole. La tesis enunciada se apoya en tres argumentos. El primero explora el sentido, la extensión y la profundidad de lo que comporta saber vivir, esto es, vivir bien. Se trata de un argumento de tipo epistemológico. El segundo afirma que saber vivir bien es un tema que se dirime de cara la naturaleza. El tercer argumento reevalúa el sentido y el significado de la filosofía de cara a las ciencias de la complejidad y explica por qué razón esto es importante. Al final se extraen algunas conclusiones.

\section{1. ¿Qué es saber vivir bien?}

No es suficiente con vivir, simplemente. Ese es, sería un tema simple y llanamente biológico. La teoría de la evolución en su versión darwiniana, y su extensión a la síntesis neodarwiniana sería suficiente para ello. El tema ciertamente hunde sus raíces en la biología, pero la supera con mucho.

Ya decía Heráclito, el Oscuro de Éfeso, que la mayoría de la gente son muertos vivientes. Zombies, diríamos hoy en día, con el trasfondo de Hollywood. "Inmortales mortales, mortales inmortales: viviendo la vida de aquellos, la vida de aquellos muriendo" (D-K, 62) (Gigon, 1971; Mondolfo, 1986; Kirk y Raven, 1981). Digámoslo de manera breve y directa: la mayoría de las gentes son muertos vivientes; y no lo saben. Y análogamente a lo que sucede con los zombies, en libros o en películas, persiguen a los vivientes y quieren matarlos para convertirlos en otros zombies. Un zombie sólo sabe de sí mismo. Significativamente, se trata de muertes vivientes sin cerebro: no piensan, no deciden, carecen de criterio propio, de cualquier sentido de autonomía, son gregarios, nada saben de imaginación y libertad, hacen lo que hacen todos los zombies. Heráclito, el preclaro.

En la Grecia antigua existían dos términos para designar a la vida: bios y zoé. El primero es idóneo tan sólo para aquellos seres que han decidido tomar el des- 
tino en sus propias manos. El segundo designa, en contraste a los vivientes en los que la vida vive a través suyo, son instrumentos. En Aristóteles, se trata de los animales; en una lectura contemporánea, se trata de todos aquellos que viven en y al servicio de Instituciones: la Iglesia, el Ejército, el Estado, la Empresa, la Corporación, o cualquier otro. Todo el pensamiento institucionalista cobra aquí sus profundas raíces.

De suerte que la vida, en su sentido primero -biosdesigna a quienes se atreven a tomar el destino en sus propias manos; y sólo éstos son verdaderamente libres. La historia, notablemente, de la literatura está repleta de casos que ilustran esta forma de vida; la única forma de vida verdadera. Pues bien, ya los griegos tenían un concepto para el bien vivir, o el saber vivir: la eupraxein, cuyo sustantivo es la eupraxis; literalmente la buena (eu) vida (praxis): eupraxía, que designaba q la felicidad, al éxito, a la capacidad de manejar bien (un navío), y también a la acción de hacer el bien. Respectivamente, en Píndaro, Las Olímpicas, 8, 14; en Tucídides, en Antifón, en Platón, en Las Leyes, 732c, en Isócrates, 197b, en Platón, en el Eutidemo, 279e, en el Alcibíades de Platón, 116b.

El eupraxein o la eupraxía designaba, pues, el saber manejar bien las situaciones, no sucumbir ante las tormentas, y hacer el bien, metafórica tanto como literalmente. Entonces, claro, se conocía el éxito y la felicidad, las cuales, como se aprecia fácilmente nada tiene que ver con grandes campañas, grandes acciones, grandes empresas, sino, siempre, con la vida cotidiana. Sabiduría pura, de la mejor.

De manera significativa, el tema se diluye a lo largo de la historia de Occidente. La religión -en rigor, las religiones monoteístas y reveladas se imponen, a sangre y fuego, imponiendo consiguientemente otras actitudes y relaciones, todas infundadas en el miedo, el castigo y sistemas punitivos. Total ausencia de libertad. Entre tanto, a lo largo de sus cerca de 2500 años, Occidente entró en una profunda crisis sistémica y sistemática. En algún momento en el ápice de esta crisis, la London School of Economics, descubre, hacia el año 2001, de un lado, que la felicidad es importante para el desarrollo de las sociedades. Este descubrimiento tiene lugar a raíz del hecho de que Bután, un pequeño país en las montañas del Himalaya, de credo budista, formuló un plan de desarrollo a cien años, cuyo primer punto era la felicidad. Jamás antes, específicamente a partir de la modernidad, la felicidad había sido considerada como un tema nacional, estratégico, de plan de desarrollo, y mucho menos a cien años vista. Desde entonces, notablemente en los indicadores Gini, se comenzó a introducir a la felicidad como un tema de desarrollo humano.

El segundo descubrimiento, casi contemporáneo al de la felicidad, fue el hecho de que los pueblos andinos -notablemente, Bolivia, Perú y Ecuador- sabían desde siempre acerca de la importancia del saber vivir y el vivir bien. Políticamente, los gobiernos de Evo Morales y de Rafael Correa estaban en su auge, digamos, como un hecho contextual. Pues bien, Occidente descubrió que la calidad de vida y la dignidad atraviesan transversalmente por un tema tan básico como eso: saber vivir bien; y de ello, significativamente, no se puede hacer un código, una política, una receta o un algoritmo. El suma qamaña y el sumak kawsay anclan profundamente en la sabiduría andina y en toda una cosmovisión uno de cuyos pilares son la lengua quechua y el aymara, lenguas vivas, a diferencia del griego antiguo y del latín.

Desde el punto de vista de las ciencias y las disciplinas, el aprendizaje -por parte de Occidente- acerca del saber vivir bien procede de la economía, se orienta hacia la historia, pero se nutre de la etnografía y la antropología. La traducción elemental consiste en lo siguiente: un sistema económico en profunda crisis sistémica y sistemática -el liberalismo, el sistema de libre mercado- necesita motivos para alimentar esperanzas acerca de un modelo en crisis y que no aguanta más; los primeros diagnósticos emergen, recientemente, a partir de los primeros Informes al Club de Roma, atraviesa por los límites planetarios del Instituto Stockholm y se proyecta en numerosos otros diagnósticos, todos similares. Al cabo, sin la menor duda, la crisis es civilizatoria. Occidente sencillamente nunca supo vivir, no supo vivir bien, y jamás hizo del tema de llevar una vida plena su principal y ni siquiera una de sus principales preocupaciones. Todo fue vida para la guerra, vida para el mercado, vida para el trabajo y la enajenación.

Vivir bien es un tema que implica, mucho más que ciencia, información y educación, además y principalmente, mucha sabiduría. Occidente jamás hizo de la sabiduría un tema mayor de consideraciones. Lo suyo fue siempre, la ciencia, la filosofía y el arte, dicho en general; ditto.

Pues bien, el tema de base radica en el reconocimiento expreso de que no existe $-y$ manifiestamente no en toda la historia de Occidente- una propedéutica, una metodología o una lógica de o hacia la sabiduría. Lo de Occidente fue siempre la fama, el éxito, la riqueza, el entendimiento, la razón y el poder; y sus variaciones y derivaciones.

Como se observa, el eupraxein y la eupraxía quedan tan sólo como referentes etimológicos y teóricos, puesto que en la experiencia de la cultura y la historia no existieron para nada, una vez que la Grecia antigua hubo desaparecido. De manera que existe un salto histórico impresionante de alrededor de 2500 años para el re-descubrimiento de aquello consistente en saber llevar una vida buena. Por consiguiente, en el reconocimiento de que temas como el poder, el éxito, la fama, 
la riqueza y el entendimiento no son precisamente los principales valores, actitudes o relaciones de una vida bien llevada. Todo un golpe para la tradición encefalocéntrica y todas sus aristas y expresiones. Dicho en el lenguaje de la economía: todo un desafío al crecimiento económico, el desarrollo, la productividad, y demás; esto es, para cualquier modelo económico de tipo productivista y, ulteriormente, extractivista.

Los pueblos, verosímilmente "atrasados", "pobres" y "subdesarrollados" de los Andes -dicho desde la perspectiva del "desarrollo" y la "gran civilización occidental"- sí han sabido lo que es vivir y llevar una vida que se define en términos significativamente mejores y muy distintas a la calidad y a la dignidad, valores distintivamente antropocéntricos y occidentales. Un motivo de reflexión.

Un rasgo sobresaliente de la sabiduría andina consiste en la ausencia de jerarquías. Antes bien, las culturas mesoamericanas y aquellas aún prevalecientes hoy en Abya Yala se organizan y viven: a) relativamente a la naturaleza, b) en términos de heterarquías (Maldonado, 2021a). En quiché, cabe mencionarlo, el verdadero poder consiste en servir a los demás, no tener fuerza, influir en los demás, tomar decisiones ("los tomadores de decisión") y cosas semejantes, de suerte que es todo lo contrario a las ideas clásicas, incluso con sus derivaciones como "empoderamiento" (horribile dictum).

Simple y llanamente vivir bien significa poner a la vida -en todas sus expresiones, niveles, manifestaciones y fenómenos- en el primer lugar, y reconocer por tanto a todo lo demás como subsidiario, en el mejor de los casos. Occidente puso en primer lugar -la lista no es en absoluto exhaustiva- a la razón, a la República, al Imperio, a la Iglesia, al Estado, al Partido, en fin, a la Empresa y la Economía (todas con mayúsculas), por ejemplo-, siempre por encima de la vida. Y por eso mismo, Occidente jamás supo de nada semejante y ni siquiera próximo a vivir bien. Elaborar esta historia, es equivalente a escribir una historia del olvido. (Para un buen conocedor algún eco heideggeriano resuena en el fondo, quedo).

Saber vivir significa que los tiempos verdaderos son los tiempos de la naturaleza, no los tiempos humanos; eufemísticamente dicho: "los tiempos de la cultura". Y los tiempos de la naturaleza poseen una densidad inmensamente mayor que los tiempos que la cultura, en cualquier acepción, en cualquier tono, en cualquier interpretación que se quiera, puedo jamás haber asumido. Veleidad y falsos sueños.

\section{Saber vivir bien es vivir con la naturaleza}

La Grecia antigua es aún pagana y politeísta, de suerte que el asunto relativo a llevar una vida buena se plantea de cualquier manera menos como una relación definitiva o determinantemente antropológica. Ciertamente que Protágoras ocupa un papel destacado cuando se indaga acerca de algo así como una antropología filosófica. En contra suya digamos dos cosas: primero, que era un sofista, lo cual a la luz de la historia oficial de la filosofía no es precisamente un cumplido. Y segundo, de manera aún más fuerte pero indirecta, que fue contemporáneo de Sócrates, y es con Sócrates, de acuerdo con la lectura de Nietzsche (2013), con quien comienza la decadencia de Occidente, la decadencia de la experiencia humana. No es éste el lugar para ponderar el juicio nietzscheano. Por ello, por politeísta y pagana aún sabía la Grecia antigua -algo- acerca del buen vivir. Pero muy pronto se imponen otras actitudes, otras creencias, otras relaciones.

Es a partir del momento en el que los seres humanos adoptan una actitud extractivista ante la naturaleza que el tema cambia por completo. Pues bien, el extractivismo comienza, mucho antes del "Génesis" en el Libro de los Libros, en la Política de Aristóteles, allí donde el Estagirita concibe a la naturaleza como un medio para los fines, necesidades e intereses de los seres humanos (Aristóteles, 1988: Libro 1).

Vivir con la naturaleza implica una fuerte distancia con respecto a las creencias, valores, comportamientos, gustos y necesidades que sugiere o impone la cultura. La cultura nos hace desear cosas que no necesitamos; particularmente en el capitalismo. Para ello, la publicidad y la propaganda, el diseño en general (diseño industrial diseño gráfico, diseño textil y otros) y el mercadeo fungen como factores determinantes para el consumo. Consumir significa crecer económicamente, de acuerdo con una creencia equivocada pero muy acendrada. Y claro, los centros comerciales están hechos para crear la sensación de libertad (Marcuse, 1969a; 1969b; 1969c). Todo se conjura para hacer a los seres humanos seres necesitantes. Nada más alejado del buen vivir.

Saber vivir bien significa, simple y llanamente, saber qué se necesita verdaderamente y qué no. Y lo cierto es que la inmensa mayoría de cosas (= productos, mercancías) no son necesarios en absoluto. La cultura ata, en tanto que la naturaleza libera.

Vivir conforme a la naturaleza significa saber a cada momento qué se necesita y qué no, qué es importante y qué es pasajero, qué es permanente y qué es aleatorio. Como se aprecia sin dificultad, el tema es filosófico en el sentido primero de las relaciones que cada quien tiene hacia los demás, hacia el mundo, hacia el tiempo y hacia la existencia misma. Saber vivir es mucho más que un asunto de ciencia en cualquier acepción de la palabra, un tema distintivo de la filosofía. No se trata 
simple y llanamente de reconocer lo que hay y cómo es y se comporta, sino de transformar la actitud o la forma de vida frente a aquello que acaece, que está ahí, lo dado y lo que clásicamente se asumió como "el ser". La filosofía es, dicho en una palabra, un llamado al cambio de la forma, el estilo, o el estándar de vida. De un lado, como un asunto personal -como en Platón o en Husserl, por ejemplo-, pero, de otra parte, además, como un tema social, colectivo o histórico -como en Spinoza o en Marx, por ejemplo-. La filosofía es un cambio de la actitud como un cambio del mundo, y no es tanto una aceptación del mundo y de las cosas como llegan o se viven como una invitación a una revuelta contra las cosas tal y como aparecen. La mayoría de filósofos han subrayado del cambio de la actitud natural hacia una actitud filosófica; algunos filósofos, han puesto de relieve el llamado a un cabio del mundo, de la sociedad, de la estructura y de la realidad misma. En este sentido, la filosofía se acerca más al arte en general que a la ciencia.

Para quien, la expresión más directa e inmediata de la naturaleza es su propio cuerpo. El cuerpo de cada quien -Leib, en su expresión en alemán, que designa al cuerpo vivo, en contraste con el Körper, que denota a los cuerpos físicos, inanes-, la experiencia más auténtica de la naturaleza en general. O también, desde otro punto de vista, la naturaleza habla a cada quien de forma inmediata a través del cuerpo y como los lenguajes del cuerpo. De esta suerte, una verdadera filosofía no es tanto filosofía de la razón, el entendimiento, la conciencia, el alma, y demás, sino, más originaria y radicalmente, es además y fundamentalmente, una filosofa del cuerpo. El cuerpo como la unidad de la vida, de tal modo que saber vivir equivale a escuchar al cuerpo y saber del cuerpo como del texto en el que se sedimenta la existencia en el sentido más pleno y fuerte de la palabra. Una sabiduría de la naturaleza es al mismo tiempo sabiduría del cuerpo.

La fenomenología de lo que ello comporta implica aspectos tales como saber alimentarse, saber amar, saber vivir el instante, saber lanzarse a los abismos como a los sueños mismo y hacer lo imposible posible y real, saber vivir con las inclemencias del tiempo y el clima tanto como con los momentos de solaz y alegría, en fin, saber que la vida es una sola y que esta ancla en el cuerpo y es desde el cuerpo mismo desde donde se lanza para que el espíritu conozca la felicidad, el conocimiento y la plenitud. Una fenomenología del cuerpo ocuparía un espacio que sobrepasa con mucho a un artículo; sin embargo, sí es posible señalar con precisión hacia las dimensiones de la sabiduría.

Una precisión, anclada en lo mejor de la ciencia de punta, se impone en este punto. La astronomía y la cos- mología, de un lado, y la física cuántica de otra parte, ponen de manifiesto que los cuerpos sólidos constituyen una ínfima minoría en la vastedad del universo. La inmensa mayoría del cosmos está vacío. Una manera puntual de señalar este hecho es el reconocimiento de que la materia bariónica compone apenas cerca del $4 \%$ del universo y que el restante $96 \%$ es energía oscura y materia oscura, y que, a la fecha, sencillamente no sabe con precisión en qué consisten. A su vez, de otra parte, la bioquímica ha puesto de relieve que de ese $4 \%$ de materia bariónica, a su vez, el átomo está esencialmente vacío, y que el cuerpo humano, la realidad y las cosas en general están vacías. Una idea manifiestamente contraintuitiva, desde donde se mire.

La conclusión no puede ser más evidente y no puede dejar de anticiparse: una filosofía de la naturaleza, como una sabiduría de la vida consisten en una ciencia, un arte, y una filosofía del vacío. He aquí el más hermoso de los oximorones: el ser es vacío (Smethan, 2010; Sabbadini, 2017; Damdul, 2019) ${ }^{1}$.

El vacío: la más contraintuitiva de las ideas en el contexto de la ciencia, la filosofía y la cultura occidentales, acostumbradas a plenitud, relleno, coseidad, fisicalidad, concreción -todas, ideas centradas en torno a la importancia de la percepción natural, y los sentidos en el sentido primero de la palabra-: lo real es lo que se ve, se toca, se coge, se siente (LeShan y Margenau, 2009; Ackerman, 1992). Pues bien, todos parece indicar que es justamente al contrario: las cosas más "reales" son intangibles, inmateriales, vacías.

Dicho de manera elemental: la sabiduría no descansa en las cosas, sino en un distanciamiento con respecto a ellas. Una idea simplemente provocadora en contextos en los que lo que se exalta es el tener, el haber, el ser, como condiciones para la calidad de vida y la dignidad de la vida. Pues bien, todos los modelos económicos pasados y vigentes ignoran completamente estas ideas. Y con ello, no pueden resolver, en absoluto, el tema del buen vivir -centrados, como lo están, en riqueza, consumo, bienestar material, crecimiento, desarrollo, y demás-. Lo anterior, sin embargo, en manera alguno de be ser entendido como una apología indirecta a la pobreza, la escasez, la exaltación de las necesidades y demás. Una pretensión semejante sería sencillamente supina.

La filosofía constituye quizás la mejor puerta de acceso a la sabiduría. Muchos más, sin ambages, que la ciencia, dicho en general.

\footnotetext{
1 Una observación puntual: no deja de ser curioso: a) que la mayoría de la bibliografía en el tema sea de autores orientales -India, Nepal, etc.), y b) que la mayoría de textos se publiquen en editoriales distintas al mainstream. Un tema relativo a la sociología del conocimiento.
} 


\section{Reevaluando la filosofía de cara a la compleji- dad}

Hemos dicho que la filosofía se distingue por ser un llamado vehemente y radical a cambiar de vida, individual o colectivamente. (Esto, dicho en passant, explica por qué razón la filosofía es políticamente incorrecta). En otras palabras, se trata de la antípoda a cualquier tipo de pensamiento de corte institucionalista, literal o metafóricamente. Antes que simplemente ver "al ser", aceptarlo tal cual es -el ser o lo que aparece, o como se quiera abordar el tema desde la epistemología; aquí da igual-, la filosofía consiste en un rechazo del ser en tanto que cambio de la actitud hacia lo que es o lo que aparece. Prácticamente toda la historia de la filosofía puede condensarse en esta idea: el Mito de la Caverna o el mito de las aguas del Río Lethé, en la República de Platón; la ironía socrática; la epojé estoica o el espíritu crítico y libre de los cínicos, la duda metódica de Descartes, el llamado a la libertad sin parangones de Spinoza, en fin, sin ser prolijos, la filosofía fenomenología de Husserl, la muy puntal tesis 11 sobre Feuerbach de Marx, la experiencia radical del rostro del otro en Lévinas, la angustia de Merleau-Ponty en el encuentro entre lo vivible y lo invisible, por ejemplo. Toda gran filosofía es una fantástica invitación a cambiar las cosas, por lo menos, cambiando la actitud ante ellas. Radicalidad, libertad, independencia.

Pues bien, existe una muy estrecha relación entre la filosofía, así entendida, y las ciencias de la complejidad (Rescher, 1998; Couloubaritsis, 2014). Las ciencias de la complejidad son ciencias de posibilidades y ciencias de la vida (Maldonado, 2021b). Y asimismo, las ciencias de la complejidad comprenden a los fenómenos, sistemas y comportamientos de complejidad creciente a partir de los grados de libertad que éstos tienen o que exhiben.

No obstante, se impone una observación importante. Pensar en términos de complejidad es bastante más y muy diferente a pensar simplemente en términos de inter, trans y multidisciplinariedad. Se trata, antes bien, de alcanzar el gran cuadro (big picture) del asunto del cual nos ocupamos, en cada caso (De Rosnay, 1977; Carroll, 2017). Dicho en términos cognitivos, pensar en complejidad es bastante más que sencillamente hacer epistemología. Importante como es, la epistemología, en toda la extensión de la palabra, es tan sólo una herramienta para una meta mayor, a saber: tener una comprensión integral, de gran alcance, a largo plazo, sobre el tema que nos ocupa en cada caso; el mundo en general, o una parte del mismo. Debemos poder superar los tecnicismos, por minimalistas, a fin de alcanzar una comprensión que implique una relación de tipo orgánico con la naturaleza o el mundo. Pues bien, una relación semejante comporta toda una forma de vida, y es bastante más que sencillamente una heurística, una lógica o una metodología.

Al mismo tiempo, es preciso observar que, bien entendidas, las ciencias de la complejidad no son más ciencia que arte, no más filosofía que ciencia, en fin, no más teoría que práctica. Los dualismos, los reduccionismos, los determinismos y los mecanicismos de cualquier índole desaparecen, se diluyen, digamos. No existen jerarquías de conocimiento, y consiguientemente tampoco jerarquías de formas o estilos de vida. Esto, a decir verdad, es algo que aún no termina de ser evidente para la gran mayoría de académicos e investigadores que trabajan en complejidad en cualquier sentido de la palabra. Existe aun implícitamente, por decir lo menos, distinciones de ciencias y disciplinas, jerarquías de lenguajes y aproximaciones.

De suerte que cuando se piensa en complejidad se piensa más allá de las distinciones entre ciencias, disciplinas, prácticas, y saberes. Un buen pensador no piensa con categorías; pensar significa, originaria, radicalmente, pensar sin categorías (Maldonado, 2019), pues las categorías nos impiden ver el mundo o la naturaleza o la vida de diversas maneras y son siempre autorreferenciales. Es justamente todo el ámbito de un pensamiento deductivo o hipotético-deductivo. Debemos poder ver el mundo sin pre-conceptos, pre-juicios, pre-comprensiones. Algo extremadamente difícil que coincide, plano por plano con la exigencia de las ciencias de la complejidad, a saber: los sistemas complejos son abiertos y para ver sistemas abiertos es indispensable tener una estructura de mente abierta. Algo que se dice fácilmente, pero es muy difícil de llevar a cabo.

Los antiguos -griegos y romanos, principalmentecreían que la filosofía es la soberana de las ciencias y las artes. Una pretensión veleidosa, si las hay. Nadie puede pretender la sabiduría afirman o creyendo en jerarquías, en parcelas, en feudos o en separaciones. Para ello contribuyen, de manera significativa, las ciencias de la complejidad. El sabio no es precisamente aquel todo lo sabe, o que sabe mucho (éste es el erudito). Mucho mejor, es aquel -o aquella- que lo comprende todo, en el sentido precisamente del big picture mencionado. Conocer o saber no cumplen necesariamente una función terapéutica o sanatoria. Por el contrario, comprender las cosas cumple una función liberadora, esperanzadora, y tanto conduce a la sabiduría como que nos transforma. El auténtico eureka no es un acto de conocimiento; es un acto de entendimiento o comprensión, dos cosas perfectamente distintas.

La ironía socrática tiene todo el sentido del mundo. Literal y metafóricamente hablando (Vlastos, 1992). Se 
trata del llamado o la invitación a reconocer que lo verdaderamente importante no consiste en saber, sino: a) en vivir lo que se sabe, y b) en entender las cosas, que es mucho más y muy diferente a simplemente conocer las cosas. Comprender nos hace libres; saber en muchas ocasiones nos ata. Digamos, obiter dictum, que los dioses de los paganos, tanto como esa diosa singular de Spinoza que es la naturaleza, no se caracterizan, en absoluto, en contraste con el El Dios Omnisciente de las tres religiones reveladas constitutivas de Occidente, por saberlo todo. Muchas cosas las ignoran; los dioses aztecas como los incas, los indios como los chinos, los escandinavos como los africanos. Pero son dioses que comprenden. Y así son más humanos que los dioses de las tres religiones del desierto.

Más humanos, es decir, más cercanos a la vida.

\section{Conclusiones}

No existe una clave, un algoritmo o una regla de oro para saber vivir bien; esto es, para llevar una vida plena. Nadie puede enseñarle a nadie a vivir bien; pero sí se puede aprender. Entre vivir bien y las ciencias de la complejidad existe una comunidad de espíritu, a saber: se trata del descrédito de cualquier semejante a una regla de oro. Este rasgo las unifica y consolida.

Este artículo es un esfuerzo por considerar en qué consiste vivir una vida buena a la luz de las ciencias de la complejidad. Si bien saber vivir es distintivamente un asunto filosófico, la filosofía no se erige como soberana de las ciencias y las artes, como querían los antiguos. Una pretensión veleidosa, a decir verdad.

Sabe vivir, llevar una vida plena o vivir bien no es tanto un asunto de conocimiento o erudición -aunque manifiestamente puede pasar por aquí; no hay absolutamente ningún problema-. Saber vivir bien significa ponderar las cosas adecuadamente; saber a qué debemos temerle y a qué no, y ser libres. Libres y felices, aunque le verdadera felicidad no siempre arranque carcajadas estruendosas, necesariamente.

Desde cualquier punto de vista, saber vivir bien significa carecer de temores, pues, en términos muy elementales, el mal puede ser identificado fácilmente en cuanto que nos roba tiempo y energías o nos introduce energías y tiempos que no nos son propios.

Con todo y una observación final: el hombre o la mujer sabios no se anuncian, no vociferan, no se venden a sí mismos. Caminan, como decía Nietzsche, por el mundo, pasos de palomas; imperceptible, acaso, invisiblemente (en contraste con los pasos y avanzadas militares y muchas otras similares). Existe, alrededor nuestro, mucha más gente que saber vivir bien, de lo que las buenas costumbres y la cultura usual parecen indicarlo. Cuando veamos a un hombre o una mujer sabios, lo mejor es acercarnos a ellos y aprender. Pues nunca enseñan; aunque si es posible aprender la sabiduría; la sabiduría: esa que no se exponen en tratados y en volúmenes enteros, sino en breves legajos sueltos, en gestos amables, allí donde emerge la serenidad y la alegría. Un tema poco obvio.

\section{Referencias bibliográficas}

Ackerman, D., (1992). Una historia natural de los sentidos. Barcelona: Anagrama

Aristóteles, (1988). Política. Madrid: Ed. Gredos

Carroll, S., (2017). The Big Picture. On the Origins of Life, Meaning, and The Universe Itself. New York: Dutton

Couloubaritsis, L., (2014). La philosophie face à la question de la complexité. Le défi majeur du $21 e$ siècle. Tome 1: Complexités intuitive, archaïque et historique. Tome 2: Complexités scientifique et contemporaine. Bruxelles: Ousia

Damdul, G. D., (2019). "Ontological Reality: Quantum Theory and Emptiness in Buddhist Philosophy", en: Bhatt, S. R., (Ed.), Quantum Reality and the Theory of Sunya, Springer Verlag, págs. 345-349; doi: 10.1007/978-981-13-1957-0_22

De Rosnay, J., (1977). El macroscopio. Hacia una visión global. Madrid: AC, D.L.

Gigon, O., (1971). Los orígenes de la filosofía griega. Madrid: Ed. Gredos

Kirk, G. S., y Raven,J. E., (1981). Los filósofos presocráticos. Historia crítica con selección de textos. Madrid: Gredos

LeShan, L., y Margenau, H., (2009). El espacio de Einstein y el cielo de Van Gogh: un paso más allá de la realidad física. Barcelona: Gedisa

Maldonado, C. E., (2021a). "La gestión compleja: de la jerarquía a las redes complejas y la heterarquía", en: Revista Ciencias de la Complejidad (próximo a publicarse)

Maldonado, C. E., (2021b) Las ciencias de la vida son ciencias de la complejidad. Santiago de Chile: Ed. Trepen

Maldonado, C. E., (2019) Turbulencias. Sobre ciencia y otras complejidades. T. I y II. Bogotá: Ed. Universidad El Bosque. Tomo I: pp. 1-486; Tomo II: pp. $1-270$

Marcuse, H., (1969a). El hombre unidimensional. Ensayo sobre la ideología de la sociedad industrial avanzada. México: Joaquín Mortiz

Marcuse, H., (1969b). Un ensayo sobre la liberación. México: Joaquín Mortiz 
Marcuse, H., (1969c). El fin de la utopía. México: Siglo XXI Editores

Mondolfo, R., (1986). Heráclito. Textos y problemas de su interpretación. Siglo XXI Editores

Nietzsche, F., (2013). El origen de la tragedia. Barcelona: Espasa Libros

Rescher, N., (1998). Complexity. A Philosophical Overview. New Brunswick and London: Transaction Publishers

Sabbadini, S. A., (2017). Pilgrimages to Emptiness.
Rethinking Reality Through Quantum Physics. Pari Publishing

Sextos Empiricus, (1990). Outines of Pyrrhonism. Translated by R. G. Bury. Buffalo, NY.: Prometheus Books

Smethan, G., (2010). Quantum Buddhism: Dancing in Emptiness - Reality Revealed at the Interface of Quantum Physics and Buddhist Philosophy. Lulu.com Vlastos, G., (1992). Socrates. Ironist and Moral Philosopher. Ithaca, N. Y.: Cornell University Press 